\title{
Atypical presentations of thrombotic thrombocytopenic purpura in middle-aged women with recurrent cerebral macrovascular thrombosis: a case report
}

\author{
Alessandro Lucchesi ${ }^{1} \cdot$ Pier Paolo Fattori $^{1} \cdot$ Sonia Ronconi $^{1} \cdot$ Silvia Carloni $^{1}$. \\ Andrea Casadei Gardini ${ }^{1} \cdot$ Gerardo Musuraca $^{1} \cdot$ Mariasanta Napolitano $^{2}$
}

Received: 14 April 2015 / Accepted: 30 May 2015

(C) Springer-Verlag Berlin Heidelberg 2015

Dear Editor,

In the current clinical practice, minimal criteria to define thrombotic thrombocytopenic purpura (TTP) are the presence of signs of microangiopathic haemolytic anaemia and low platelet (PLT) count [1]. TTP relapses (20-50\% of cases) are defined as the recurrence of acute TTP symptoms 30 days after the first episode, while exacerbations occur within 30 days [2]. We here report on an atypical case of acquired TTP where minimal criteria were met only after many recurrent macrovascular ischemic events.

A 42-year old Caucasian woman with a history of coronary and cerebral ischemic events was admitted on June 2013, following a recurrent transient ischemic attack (TIA). She had severe anaemia and thrombocytopenia with laboratory signs of intravascular haemolysis and mild renal impairment. In her past medical history, recurrent ischemic events occurred from 2008 to 2012, without known risk factors and regardless of treatment. The patient was treated with acetyl salicylic acid (100 mg daily) after the first ischemic event (stroke,

Alessandro Lucchesi

alessandro.lucchesi@irst.emr.it

1 Department of Medical Oncology, Istituto Scientifico Romagnolo per lo Studio e la Cura dei Tumori (IRST) IRCCS, Via P. Maroncelli 40, 47014 Meldola, FC, Italy

2 U.O. Ematologia con Trapianto, Policlinico“Giaccone”, Università di Palermo, Palermo, Italy in 2008) plus anticoagulation with warfarin after the third stroke (in 2010), with a good compliance. Screening for autoimmune disease, Factor $\mathrm{V}$ Leiden and Factor II (G20210A) gene mutations and circulating anticoagulants were normal. Blood cell count and peripheral blood smear did not show any significant abnormalities in the past, without evidence of schistocytes; a slight decrease in PLT count $(92 \times 109 / \mathrm{L})$ was observed only once (in 2012), at that time, ADAMTS13 activity (ADAMTS-13: AC) was $65 \%$. At the current admission, ADAMTS-13: AC was $6 \%$, inhibitors were at high titer (2 Bethesda Units, BU). A genetic test for Upshaw-Schülman syndrome was normal. Therapeutic plasma exchange (TPE) and prednisone $(1 \mathrm{mg} / \mathrm{kg}$ body weight) treatment was started and maintained until clinical and haematological remission [3]. TPE (Gambro ${ }^{\circledR}$, Italy) was performed daily for 3 weeks with an increase of ADAMTS13: AC to $50 \%$. TTP exacerbated after 10 days, it was well controlled with weekly rituximab ( $375 \mathrm{mg} / \mathrm{m}^{2}$ body surface), for 4 weeks. A relapse occurred after 37 days with the patient presenting seizures: ADAMTS-13: AC, which was $54 \%$ after the last treatment, had decreased to $6 \%$. A second course of weekly rituximab, followed by maintenance with azathioprine (50 mg twice daily for 10 days, then $50 \mathrm{mg}$, daily) was followed by clinical and haematological remission. Rituximab was re-administered for its previous rapid efficacy and to prevent further complications [4]. The patient is alive and free from recurrences for 18 months; azathioprine maintenance is still on course. ADAMTS13: AC is monitored every 4 months, and it ranges from 45 to $51 \%$; inhibitors are no longer detectable. 


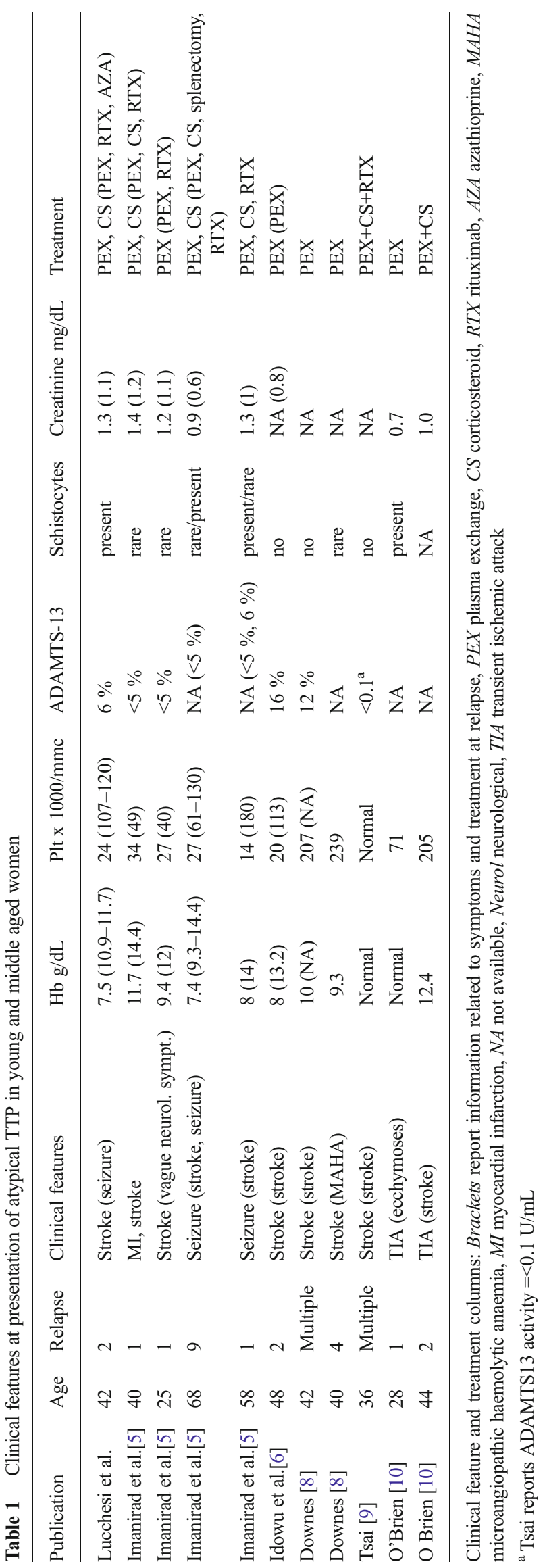

We hypothesize that the disease occurred in 2008, with a chronic relapsing behaviour and a more acute phase only in 2013. Ten similar cases have been reported [5-10] (Table 1). In atypical TTP recurrences, symptoms mainly guide treatment at recurrence. Most of the described cases recovered after the administration of rituximab or immunosuppressive agents.

Our case was especially atypical because it became manifested only after years during which even minimal criteria for TTP diagnosis were not met and ADAMTS13: AC was normal.

When macrovascular ischemic events are not accompanied by anaemia or thrombocytopenia, TTP is rarely taken into account.

However, TTP should be considered even with only slight laboratory and haematological abnormalities.

Acknowledgments The author thanks Ursula Elbling for editing the manuscript. Written informed consent was obtained from the patient for publication of this case report and accompanying data.

Conflict of interest The authors declare that they have no conflict of interest.

\section{References}

1. George JN, Sadler JF, Lämmle B (2002) Platelets: Thrombotic Thrombocytopenic purpura. Hematology Am Soc Hematol Educ Program 2002:315-334. doi:10.1182/asheducation-2002.1.315

2. Chapman K, Seldon M, Richards R (2012) Thrombotic microangiopathies, thrombotic thrombocytopenic purpura, and ADAMTS13. Semin Thromb Hemost 38:47-54

3. Scully M, Hunt BJ, Benjamin S, Licenser R, Rose P, Peyvandi F, Cheung B, Machin SJ (2012) British Committee for Standards in Haematology. Guidelines on the diagnosis and management of thrombotic thrombocytopenic purpura and other thrombotic microangiopathies. Br J Haematol 158:323-335

4. Stein GY, Zeidman A, Fradin Z, Varon M, Cohen A, Mittelman M (2004) Treatment of resistant thrombotic thrombocytopenic purpura with rituximab and cyclophosphamide. Int J Hematol 80:94-96

5. Imanirad I, Rajasekhar A, Zumberg M (2012) A case series of atypical presentations of thrombotic thrombocytopenic purpura. J Clin Apher 27:221-226

6. Idowu M, Reddy P (2013) Atypical thrombotic thrombocytopenic purpura in a middle-aged woman who presented with a recurrent stroke. Am J Hematol 88:237-239

7. Sarode R (2009) Atypical presentations of thrombotic thrombocytopenic purpura: a review. J Clin Apher 24:47-52

8. Downes KA, Yomtovian R, Tsai HM, Silver B, Rutherford C, Sarode R (2004) Relapsed thrombotic thrombocytopenic purpura presenting as an acute cerebrovascular accident. J Clin Apher 19(2): $86-89$

9. Tsai HM, Shulman K (2003) Rituximab induces remission of cerebral ischemia caused by thrombotic thrombocytopenic purpura. Eur J Haematol 70(3): 183-185

10. O'Brien TE, Crum ED (2002) Atypical presentations of thrombotic thrombocytopenic purpura. Int $\mathrm{J}$ Hematol 76(5): 471-473 